\title{
West Nile Virus Nervous System Manifestations
}

\author{
Mervat Wahba* \\ Department of Neurology, University of Tennessee Health Sciences Center, USA
}

*Corresponding author: Mervat Wahba, Associate Professor of Neurology,

University of Tennessee Health Sciences Center, Tennessee, USA.

Received Date: October 11, 2018

Published Date: October 23, 2018

\section{Review}

West Nile Virus (WNV) is a member of the Flaviviridae, a family of single-stranded RNA viruses transmitted by the Culex mosquitoes and is characterized by the presence of neuro invasive strains causing disease and death in humans, birds and horses. While long identified in Africa, and other parts of the world, WNV was first diagnosed in North America in 1999, causing a surge in the number of WNV-related neuro invasive cases in 2002-2003, and again in 2012.

West Nile virus is spread between birds by mosquitoes. It is maintained in the wild bird population. Humans and horses become infected after being bitten by mosquitoes harboring the virus that have fed on infected birds. The virus enters the horse's bloodstream and spreads to the spinal cord and brain causing inflammation. Clinical signs of disease usually present within three to fifteen days of exposure [1-3].

\section{History and Epidemiology}

West Nile virus was first isolated in Uganda in 1937, it has since become endemic in some parts of Africa where the prevalence of WNV antibody among children may be up to 8\% [3-5]. WNV disease first appeared in North America in the summer of 1999, when an unusual number of deaths of exotic birds and crows in the New York City (NYC) Metropolitan Area was reported.

\section{Transmission}

Transmission of WNV to humans occurs mostly following a bite from an infected mosquito, which acquires the virus after feeding on amplifying hosts, namely birds. WNV is primarily transmitted by Culex mosquitoes. However, the virus has been isolated from more than 60 species of mosquitoes, as well as from ticks [6]. Person-toperson transmission of WNV only occurs as a result of transfusion of blood products and organ transplantation, as well as following intrauterine, percutaneous (occupational) or breastfeeding exposure [7]. WNV may be transmitted from mother to child by intrauterine transmission causing chorioretinitis, microcephaly and intracranial calcifications [8].

\section{Clinical Features}

Several clinical features may support the diagnosis of CNS infection with WNV. Symptoms of fever (in $70-100 \%$ of patients), headache (50-100\%) and altered mental status (50-100\%) are common. Vomiting (30-75\%), diarrhea (15-35\%) and rash (5-50\%) are seen in a significant percentage of patients [9-11]. Meningoencephalitis may occur in $30-50 \%$ and is often of a lowermotor-neuron pattern with flaccid paralysis without sensory abnormalities [12]. Bilateral facial nerve palsy may occur during the second or third week of the illness. Movement disorders such as dyskinesias are common in patients with WNV meningoencephalitis and may include postural or kinetic tremor in up to $90 \%$ of the patients, parkinsonism including cogwheel rigidity, bradykinesia and postural instability, and myoclonus may also occur [12].

Acute flaccid paralysis may occur in isolation, or in association with meningitis or meningoencephalitis in up to $50 \%$ of cases [13]. In West Nile Virus infection, motor weakness results from a poliomyelitis-like process presenting as pure motor deficit, unlike Guillain-Barré syndrome that presents with motor as well as sensory symptoms. Guillain-Barré-like syndrome affecting peripheral nerves, radiculopathy and demyelinating peripheral neuropathy have also been reported, however true Guillain-Barré syndrome is rare. Respiratory failure requiring endotracheal intubation, is seen in $38 \%$ of affected patients in a recent series. Bowel and bladder dysfunction occur in a third of patients [12].

\section{Laboratory Findings}

Complete blood counts may initially show minor abnormalities, however, there may be absolute or relative lymphopenia [14]. Up to one third of the patients develop significant hyponatremia, secondary to syndrome of inappropriate antidiuretic hormone 
secretion (SIADH). This may be noted during the acute illness or in the recovery period [15]. Cerebrospinal fluid pleocytosis is noted with an initial neutrophilic predominance, followed by lymphocytic predominance in the second week. Proteins are usually moderately to severely elevated (up to $300 \mathrm{mg} / \mathrm{dL}$ ), and CSF glucose is usually normal $[16,17]$. An acute WNV infection is diagnosed by detecting the virus itself by a positive real-time polymerase chain reaction (RT-PCR), which has a sensitivity of 55\% in the CSF and $10 \%$ in the serum. This test detects IgM antibodies in the CSF by enzymelinked immunosorbent assay (ELISA) method; demonstrating more than a fourfold increase in the titer of the specific neutralizing antibody [15]. IgM ELISA in the serum has a sensitivity of $95 \%$ and a specificity of $90 \%$ when done within 8 days of the symptom onset.

\section{Radiological Findings}

In a recent series reporting 39 consecutive cases of WNV including both meningitis and meningoencephalitis, MRI was unremarkable in all except one patient [18]. In two more recent case series $[19,20]$, around $70 \%$ of patients with WNV CNS disease had abnormal MRI findings. Patients with normal MRI or only DWimage abnormalities had the best prognosis, whereas those with T2 and FLAIR abnormalities had the worst outcomes.

\section{Prognosis of West Nile Virus Disease}

The overall case-fatality rate for WNV infection is 2-7\%, based on US cases by the CDC report from 2002-2005. Mortality is mostly reported in patients with neuroinvasive disease with meningitis or meningoencephalitis in whom the death rate may reach 9\%. In patients with WNV encephalitis, the overall mortality is approximately $12-15 \%$, although it could be as high as $35 \%$ in elderly patients [21] Most patients with WNV meningitis without focal neurological deficits make a complete recovery. Long-term outcomes of WNV-related severe neurological deficits may persist for months or even years [12]. Younger age at infection may be a predictor of recovery. A recent study indicated that patients with normal MRI, or with abnormalities detected only on DW images, had better outcomes that those with abnormalities on FLAIR and T2-weighted images [19].

Patients with acute flaccid paralysis often have significant residual weakness. In a prospective study of 32 patients with WNVassociated paralysis, 25 showed varying degrees of improvement at 4 months after the onset of symptoms, and the remaining 7 patients showed no improvement [22,23].

\section{Therapeutics}

Current management of WNV disease is mainly supportive, including pain control for headaches, antiemetic therapy and rehydration for associated nausea and vomiting. Monitoring and treatment of increased intracranial pressure or controlling seizures if they occur. Preventative measures include wearing protective clothing, applying insect repellents such as $10 \%$ to $50 \% \mathrm{~N}, \mathrm{~N}$ diethyl-3-methylbenzamide, and avoiding activities in areas and times when mosquitoes are most active area advisable.
There are numerous case series reporting on the use of various products such as standard and hyperimmune polyclonal immune globulin, monoclonal immune globulin, interferon, ribavirin, and corticosteroids in patients with WNV disease. Several of these products have been studied in controlled clinical trials for infections due to WNV or closely related flaviruses (i.e., St. Louis encephalitis and Japanese encephalitis viruses). According to these studies, none have shown benefit. However, the studies often had small sample sizes and the results from some of the clinical trials have not been published [24]. Physicians have chosen to treat cases of WNV with concomitant immunosuppression.

Winston et al. [25] published a case series where they reported the use of polyclonal intravenous immune globulin (IGIV) to treat four patients with WNV disease transmitted through organ transplantation. All received $500 \mathrm{mg} / \mathrm{kg}$ per day IGIV but for variable numbers of days. In addition to IGIV, two patients received interferon-alpha $2 b$, one patient received interferon- $\alpha 2 b$ and WNV IgG-positive plasma, and one patient received ribavirin. Two patients died and two survived; one of the survivors received a second liver transplant at 27 days after the first procedure. In the authors review of the literature of transplant recipients with donor-derived WNV infection, three $(43 \%)$ of seven patients with encephalitis treated with IGIV alone or IGIV with WNV-IgG containing plasma improved, and all four patients with asymptomatic WNV infection treated with IGIV or plasma survived. However, five (71\%) of seven transplant recipients with encephalitis and receiving only supportive care also improved.

Kumar et al. [26] conducted A controlled study in India in 2005-2007 randomizing children with Japanese encephalitis to receive ribavirin (10 $\mathrm{mg} / \mathrm{kg}$ per day for 7 days) or placebo. Japanese encephalitis virus is a flavivirus that is closely related to WNV. There was no difference between the two groups in mortality. There were also no statistically significant differences in secondary outcome measures.

Ribavirin appears to have limited clinical efficacy despite demonstrated efficacy against WNV in vitro $[27,28]$. Inhibitors of nucleoside triphosphatase (NTPase)/helicase activities of Flaviviridae have not shown promising results against WNV in vitro [29] The efficacy of IFN treatment in humans is still unclear, as it has only been studied in a non-blinded, non-placebo-controlled clinical trial. A vaccine has been developed for veterinary use in horses, no vaccines are yet approved for use in humans.

\section{Conclusion}

WNV was first isolated more than eighty years ago. It became a worrisome flavivirus as it has invaded North America and became the most frequent cause of epidemic meningoencephalitis in humans in North America. Although less than 1\% of infected individuals develop neuroinvasive disease as meningitis, meningoencephalitis or acute flaccid paralysis, mortality is high in this group of patients. No specific therapy has yet been shown to be effective for treatment of WNV encephalitis. Antiviral therapy, 
immunomodulatory therapies and vaccines, are currently areas of research.

\section{Acknowledgement}

None.

\section{Conflict of Interest}

No Conflict of interest.

\section{References}

1. Marfin AA, Gubler DJ (2001) West Nile encephalitis: An emerging disease in the United States. Clin Infect Dis 33(10): 1713-1719.

2. Petersen LR, Marfin AA, Gubler DJ (2003) West Nile virus. JAMA 290(4): 524-528.

3. Iyer AV, Kousoulas K (2013) A Review of Vaccine Approaches for West Nile Virus. Int J Environ Res Public Health 10(9): 4200-4223.

4. Corwin A, Habib M, Olson J, Scott D, Ksiazek T, et al. (1992) The prevalence of arboviral, rickettsial, and Hantaan-like viral antibody among schoolchildren in the Nile river delta of Egypt. Trans R Soc Top Med Hyg 86(6): 677-679.

5. Batieha A, Saliba EK, Graham R, Mohareb E, Hijazi Y, et al. (2000) Seroprevalence of West Nile, Rift Valley, and sandfly arboviruses in Hashimiah, Jordan. Emerg Infect Dis 6(4): 358-362.

6. Gubler DJ (2007) The continuing spread of West Nile virus in the western Hemisphere. Clin Infect Dis 45(8): 1039-1046.

7. Tyler KL (2004) West Nile virus infection in the United States. Arch Neurol 61(8): 1190-1195.

8. Centers for Disease Control and Prevention (2004) Interim guidelines for the evaluation of infants born to mothers infected with West Nile virus during pregnancy. MMWR Morb Mortal Wkly Rep 53(7): 154-157.

9. Centers for Disease Control and Prevention (2002) Laboratory-acquired West Nile virus infections-United States, 2002. MMWR Morb Mortal Wkly Rep 51(50): 1133-1135.

10. Hayes EB, Sejvar JJ, Zaki SR, Lanciotti RS, Bode AV, et al. (2005) Virology, pathology, and clinical manifestations of West Nile virus disease. Emerg Infect Dis 11(8): 1174-1179.

11. Petersen LR, Roehrig JT, Hughes JM (2002) West Nile virus encephalitis. N Engl J Med 347(16): 1225-1226.

12. Sejvar JJ, Haddad MB, Tierney BC, Campbell GL, Marfin AA, et al. (2003) Neurologic manifestations and outcome of West Nile virus infection. JAMA 290(4): 511-515.

13. Sejvar JJ, Bode AV, Marfin AA, Campbell GL, Ewing D, et al. (2005) West Nile virus-associated flaccid paralysis. Emerg Infect Dis 11(7): 10211027.

14. Hirsch MS, Werner B (2003) Case records of the Massachusetts General Hospital. Weekly clinicopathological exercises. Case 17-2003. A 38-year- old woman with fever, headache, and confusion. N Engl J Med 348(22): 2239-2247.

15. Nash D, Mostashari F, Fine A, Miller J, O'Leary D (2001) The outbreak of West Nile virus infection in the New York City area in 1999. N Engl J Med 344(24): 1807-1814.

16. Jeha LE, Sila CA, Lederman RJ, Prayson RA, Isada CM (2003) West Nile virus infection: A new acute paralytic illness. Neurology 61(1): 55-59.

17. Pepperell C, Rau N, Krajden S, Kern R, Humar A (2003) West Nile virus infection in 2002: Morbidity and mortality among patients admitted to hospital in southcentral Ontario. CMAJ 168: 1399-1405.

18. Brilla R, Block M, Geremia G, Wichter M (2004) Clinical and neuroradiologic features of 39 consecutive cases of West Nile Virus meningoencephalitis. J Neurol Sci 220(1-2): 37-40.

19. Ali M, Safriel Y, Sohi J, Llave A, Weathers S (2005) West Nile virus infection: MR imaging findings in the nervous system. AJNR Am J Neuroradiol 26(2): 289-297.

20. Petropoulou KA, Gordon SM, Prayson RA, Ruggierri PM (2005) West Nile virus meningoencephalitis: MR imaging findings. AJNR Am J Neuroradiol 26(8): 1986-1995.

21. Centers for Disease Control and Prevention.

22. Sejvar JJ, Bode AV, Marfin AA, Campbell GL, Ewing D, et al. (2005) West Nile virus-associated flaccid paralysis. Emerg Infect Dis 11(7): 10211027.

23. Marciniak C, Sorosky S, Hynes C (2004) Acute flaccid paralysis associated with West Nile virus: motor and functional improvement in 4 patients. Arch Phys Med Rehabil 85(12): 1933-1938.

24. h t t p : / / c l i n i c a l t r i a l s. g o v/ct $2 /$ results?term=west+nile+virus\&Search=Search

25. Winston DJ, Vikram HR, Rabe IB, Dhillon G, Mulligan D, et al. (2014) The West Nile Virus Transplant-Associated Transmission Investigation Team. Donor-derived west nile virus infection in solid organ transplant recipients: report of four additional cases and review of clinical, diagnostic, and therapeutic features. Transplantation 97(9): 881-889.

26. Kumar R, Tripathi P, Baranwal M, Singh S, Tripathi S, et al. (2009) Randomized, controlled trial of oral ribavirin for Japanese encephalitis in children in Uttar Pradesh. Clin Infect Dis 48(4): 400-406.

27. Chowers MY, Lang R, Nassar F, Ben-David D, M Giladi M, et al. (2001) Clinical characteristics of the West Nile fever outbreak, Israel, 2000. Emerg Infect Dis 7: 675-678.

28. Bretner M, Schalinski S, Haag A, Lang M, Schmitz H, et al. (2004) Synthesis and evaluation of ATP-binding site directed potential inhibitors of nucleoside triphosphatases/helicases and polymerases of hepatitis C and other selected Flaviviridae viruses. Antivir Chem Chemother 15: $35-42$.

29. Morrey JD, Day CW, Julander JG, Blatt LM, Smee DF, et al. (2004) Effect of interferon-alpha and interferon-inducers on West Nile virus in mouse and hamster animal models. Antivir Chem Chemother 15(2): 101-109. 